\title{
Systemic amyloidosis: A rare presentation of mesenteric angina
}

\author{
Christopher N Andrews $\mathrm{MD}^{1}$, Jack N Amar MD FRCPC ${ }^{2}$, \\ Malcolm MM Hayes MBChB FRCPC ${ }^{3}$, Robert A Enns MD FRCPC ${ }^{2}$
}

CN Andrews, JN Amar, MMM Hayes, RA Enns. Systemic amyloidosis: A rare presentation of mesenteric angina. Can J Gastroenterol 2002;16(10):683-685.

A 64-year-old man presented with an eight-month history of increasing postprandial epigastric pain and a $15 \mathrm{~kg}$ weight loss. Computed tomography of the abdomen, panendoscopy and mesenteric angiography failed to explain the cause of the patient's mesenteric angina. Systemic amyloidosis involving intestinal small vasculature without larger arterial involvement was diagnosed at autopsy after the patient died of an asystolic cardiac arrest. Mesenteric angina without evidence of ischemic enteritis or pseudo-obstruction is a rare manifestation of amyloidosis.

Key Words: Abdominal pain; Amyloidosis; Ischemia; Mesentery
Infarctus mésentérique : manifestation rare de l'amylose généralisée

RÉSUMÉ: Un homme de 64 ans est venu consulter pour des douleurs épigastriques postprandiales se faisant de plus en fortes depuis huit mois et une perte de poids de $15 \mathrm{~kg}$. Une tomodensitométrie de l'abdomen, une panendoscopie et une angiographie du mésentère n'ont pas permis de cerner la cause de l'infarctus mésentérique. Finalement, une amylose généralisée touchant les petits vaisseaux sanguins de l'intestin mais pas les grosses artères a été diagnostiquée à l'autopsie après que le patient eu succombé à un arrêt cardiaque par asystole. L'infarctus mésentérique en l'absence d'entérite ischémique ou de pseudo-obstruction est une manifestation rare de l'amylose. myloidosis is a disease characterized by the accumula-
tion of various insoluble fibrillar proteins (amyloid) in
extracellular tissue. These fibrils are made of low molecular
weight subunits of a variety of normal serum proteins and
accumulate in amounts sufficient to impair normal organ
function (1).
Systemic amyloidosis can affect any part of the gastroin-
testinal (GI) tract from the mouth to the anus, and can also cause hepatic and pancreatic disease. Clinical manifestations are numerous; this report describes an unusual case of systemic amyloidosis presenting as mesenteric angina.

\section{CASE PRESENTATION}

A 64-year-old black man who immigrated to Canada from the Caribbean in 1965 was well until 10 months before admission, when he suffered a left hemispheric cerebral vas-

\footnotetext{
${ }^{1}$ Department of Medicine, University of British Columbia, and Departments of ${ }^{2}$ Gastroenterology and ${ }^{3}$ Pathology, St Paul's Hospital, Vancouver, British Columbia

Correspondence and reprints: Dr Robert A Enns, Department of Gastroenterology, St Paul's Hospital, \#300-1144 Burrard Street, Vancouver,

British Columbia V6Z 2A5. Telephone 604-688-7017, fax 604-689-2004, e-mail renns@interchange.ubc.ca

Received for publication June 10, 2002. Accepted August 15, 2002
} 
cular accident with a mild residual deficit. Investigations revealed atrial fibrillation; therefore, he was started on a beta-blocker and anticoagulated with warfarin. He was not taking any other medications.

Two months later, he developed anorexia associated with increasing epigastric pain. The pain would typically start 30 to $60 \mathrm{~min}$ after ingestion of solids or liquids, and would remit between meals. High calorie liquids seemed to cause more pain than did water or tea. He was treated with an acid suppression agent by his family physician with no relief. The pain was severe enough that the patient had stopped eating on many occasions, and he lost approximately $15 \mathrm{~kg}$ over the next six months. He denied any diarrhea, melena, hematochezia, steatorrhea, dysphagia, reflux or fever. He had occasional episodes of nonbloody vomiting in the 10 days before admission. He was admitted to hospital for further investigation.

On examination, he appeared adequately nourished. $\mathrm{He}$ was normotensive, with a regular pulse of 80 beats/min, and was afebrile. Cardiac and respiratory examinations were unremarkable with the exception of a soft systolic murmur at the left sternal border. There were no stigmata of chronic liver disease. Abdominal examination revealed no abnormalities. Digital rectal examination revealed guaiacpositive stool but was otherwise unremarkable.

Laboratory investigations revealed a normocytic anemia with hemoglobin of $100 \mathrm{~g} / \mathrm{L}$. Electrolytes, urea, creatinine, aspartate aminotransferase, alanine aminotransferase and amylase levels were within normal ranges. Gamma glutamyltranspeptidase was elevated at twice normal, and lactate dehydrogenase was slightly elevated. There was a persistent unconjugated hyperbilirubinemia between 23 $\mu \mathrm{mol} / \mathrm{L}$ and $39 \mu \mathrm{mol} / \mathrm{L}$ (normal less than $20 \mu \mathrm{mol} / \mathrm{L}$ ), and it was questioned whether the patient had Gilbert's syndrome. Serum protein electrophoresis showed low albumin at $27 \mathrm{~g} / \mathrm{L}$ (normal $35 \mathrm{~g} / \mathrm{L}$ to $48 \mathrm{~g} / \mathrm{L}$ ) and low total protein at $47 \mathrm{~g} / \mathrm{L}$ (normal $60 \mathrm{~g} / \mathrm{L}$ to $80 \mathrm{~g} / \mathrm{L}$ ) but was otherwise normal. Serum lactate was initially slightly elevated at $2.5 \mathrm{mmol} / \mathrm{L}$ (normal $0.5 \mathrm{mmol} / \mathrm{L}$ to $2.1 \mathrm{mmol} / \mathrm{L}$ ), but normalized on subsequent readings following rehydration.

Tumour markers carcinoembryonic antigen and CA19 were not elevated. Urinalysis showed no proteinuria. Blood cultures were negative. His electrocardiogram was reported as normal sinus rhythm with no new changes compared with previous readings.

Chest radiography revealed a trace of pleural fluid, but was otherwise normal. Abdominal ultrasound showed no abnormalities. Computed tomography of the abdomen with contrast showed a normal liver, gallbladder, spleen, pancreas, adrenal glands and lung bases.

With no obvious explanation for the patient's epigastric pain, endoscopic investigations were undertaken. Gastroscopy revealed some patchy erythema in the body of the stomach, which was not felt to be a significant source of the patient's abdominal pain and weight loss. Biopsy samples revealed Helicobacter pylori gastritis. Small bowel appearance was normal on enteroscopy. Colonoscopy was unremarkable except for a small cecal polyp with a benign appearance. The patient was pain free during all endoscopic investigations.

A ${ }^{99} \mathrm{~m}$ Tc-Disofenin biliary scan demonstrated good hepatocyte function with patent cystic and common bile ducts. Barium small bowel follow-through examination was normal, with no evidence of obstruction or ileus.

Mesenteric angiography was performed. This revealed widely patent celiac axis and superior and inferior mesenteric arteries, with no evidence of atherosclerosis. There was no evidence of peripheral stenoses or emboli.

With still no cause found for the patient's ongoing pain, it was elected to perform endoscopic retrograde cholangiopancreatography. An $8 \mathrm{~mm}$ gallstone was found in the mid-common bile duct. Sphincterotomy and the stone extraction, unfortunately, did not improve his pain. It was thought that a cholecystectomy and/or laparotomy might be the next step because the exhaustive work-up had failed to reveal any clear cause for the patient's pain and weight loss, which continued in hospital. Two days later the patient experienced sudden onset shortness of breath, went into asystolic cardiac arrest and died despite resuscitation attempts.

Autopsy subsequently revealed severe diffuse systemic amyloidosis resulting in virtual obliteration of small- to medium-sized arterial and venous vessels throughout the body, including in the the mesentery and bowel wall. There was no evidence of bowel infarction premorbidly.

Extensive amyloid deposition was also found in most organs, including myocardium, kidneys, liver, bladder and brain (the apparent cause of his previous stroke). There was no evidence of multiple myeloma, underlying chronic inflammatory disease or lymphoproliferative disorder. Review of antemortem gastric biopsies revealed a nonsignificant amount of amyloid. Cause of death was ascribed to a cardiac arrhythmia secondary to amyloid-induced cardiomyopathy.

\section{DISCUSSION}

Four major types of amyloid and several less common forms have been described $(1,2)$. Primary amyloidosis (AL), the most common form, results from fibril formation from fragments of monoclonal antibody light chains and is associated with multiple myeloma in up to $20 \%$ of patients (1). The remainder of $\mathrm{AL}$ patients have an idiopathic etiology. Secondary (reactive, or AA) amyloidosis fibrils are composed of fragments of the acute phase reactant serum amyloid $\mathrm{A}$, and occur most frequently as a complication of chronic inflammatory diseases, such as rheumatoid arthritis, tuberculosis and occasionally inflammatory bowel disease. Other common types are familial and hemodialysis-related forms.

Diagnosis of amyloid is established by Congo red staining of a tissue specimen, which imparts a characteristic green birefringence when viewed with polarized light (1). 
Immunofixation tests are available to identify the AL amyloid subtype, the most common form. This testing was not performed in this patient, so the specific amyloid type is not known. However, because chronic inflammatory disease was not clinically suspected nor found on autopsy, his family history was negative for amyloid-like disease, and he was not on hemodialysis, it suggests that the patient had the most common, idiopathic AL form.

Whether amyloidosis is systemic or localized, the severity of the organ dysfunction is mostly a determinant of the biochemical properties of the specific amyloid protein (2). GI disease is present in up to $60 \%$ of patients with AA, but is less common in $\mathrm{AL}$ amyloidosis (3). A retrospective review from the Mayo Clinic (Rochester, Minnesota) found that only $8 \%$ of 769 patients with AL amyloidosis had GI involvement on biopsy (4). Of patients with biopsy-proven GI amyloidosis, the most common sites of amyloid deposition are the duodenum $(100 \%)$, stomach $(95 \%)$, colorectum (91\%) and esophagus (72\%) (5).

Clinically, although autopsy results have shown GI involvement in most patients with amyloidosis, symptoms are surprisingly rare (6). Symptoms can result from amyloid deposition in the autonomic nervous system or from direct infiltration of the GI tract itself. Described syndromes include: GI bleeding (from ulcers, nodularity or polypoid lesions) (5), malabsorption $(1,7)$, chronic dysmotility (presenting as dysphagia, gastroparesis, constipation or pseudoobstruction) (3), protein-losing gastroenteropathy (8),

\section{REFERENCES}

1. Sipe JD, Cohen AS. Amyloidosis. In: Fauci AS, Braunwald E, Isselbacher KJ, eds. Harrison's Principles of Internal Medicine, 14th edn. New York: McGraw-Hill, 1998:1856-60.

2. Falk RH, Comenzo RL, Skinner M. The systemic amyloidoses. N Engl J Med 1997;337:898-909.

3. Friedman S, Janowitz HD. Systemic amyloidosis and the gastrointestinal tract. Gastroenterol Clin N Am 1998;27:595-614.

4. Menke DM, Kyle RA, Fleming CR, et al. Symptomatic gastric amyloidosis in patients with primary systemic amyloidosis. Mayo Clin Proc 1993;68:763-7.

5. Tada S, Iida M, Iwashita A, et al. Endoscopic and biopsy findings of the upper digestive tract in patients with amyloidosis. Gastrointest Endosc 1990;36:10-4. intestinal obstruction from amyloid tumours (9) and intestinal perforation (10)

Abdominal pain as a major symptom in GI amyloidosis is less common. In the above mentioned article by Menke (4), of 59 patients with gastric amyloidosis, only eight were symptomatic; none described abdominal pain. Lee et al (7) reviewed 40 patients with amyloidosis, of whom 12 (30\%) had abdominal pain, but only two of them had pain as their chief complaint.

This patient described classic mesenteric ischemia symptoms with postprandial abdominal pain 30 to 60 min after eating, that remitted when the stomach was empty. $\mathrm{He}$ developed a fear of eating and subsequently lost $15 \mathrm{~kg}$. These symptoms arise from decreased splanchnic blood flow usually as a result of atherosclerotic disease, with multiple large vessel stenoses. This patient had widely patent larger arteries but virtual obliteration of smaller mesenteric vasculature from amyloid deposits, giving a normal angiographic picture but identical symptoms.

Additionally, although ischemic colitis has been described as a result of amyloidosis (7), this patient had no evidence of ischemia on enteroscopy or full colonoscopy. This constellation of symptomatology and normal radiographic, endoscopic and angiographic findings is novel and has not been reported to our knowledge. Mesenteric angina symptoms, though rare, should be considered one of the protean manifestations of gastrointestinal amyloidosis.

6. Gilat T, Revach M, Sohar E. Deposition of the amyloid in the gastrointestinal tract. Gut 1969;10:98-104.

7. Lee JG, Wilson JAP, Gottfried MR. Gastrointestinal manifestations of amyloidosis. South Med J 1994;87:243-7.

8. Suzuki C, Higaki S, Nishiaki M, et al. $99 \mathrm{mTc}-\mathrm{HAS}-\mathrm{D}$ scintigraphy in the diagnosis of protein-losing gastroenteropathy due to secondary amyloidosis. J Gastroenterol 1997;32:78-82.

9. Baldewijns M, Ectors N, Verbeeck G, et al. Intermittent subobstruction and cholestasis as complications of duodenal amyloid tumours. Gastroenterol Clin Biol 1995;19:218-21.

10. Thaler W, Schatzer G, Eder P, Fichtel G. Amyloidosis - an unusual case of recurrent intestinal bleeding and sigmoid perforation: Case report with review of the literature. Int J Colorectal Dis 1999;14:297-9. 


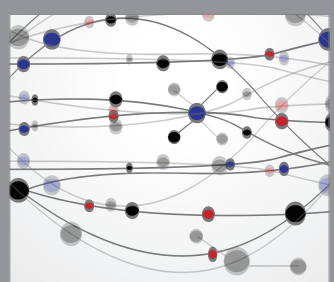

The Scientific World Journal
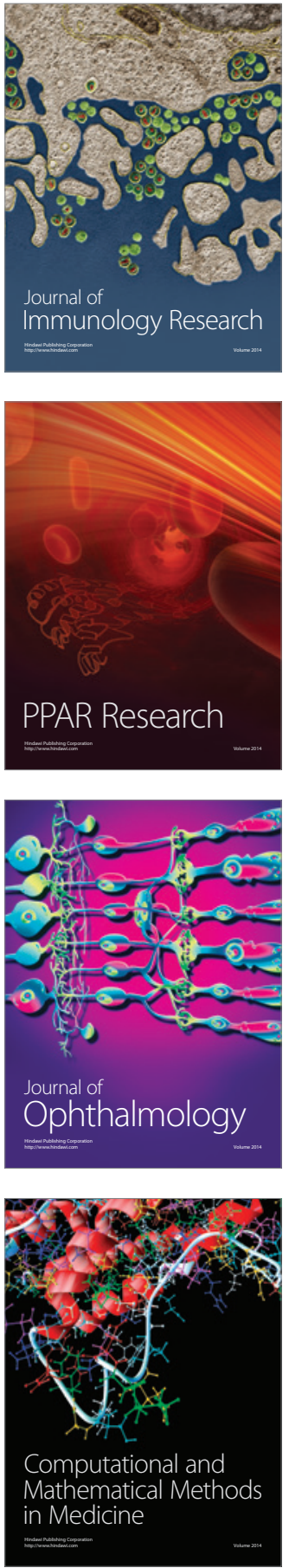

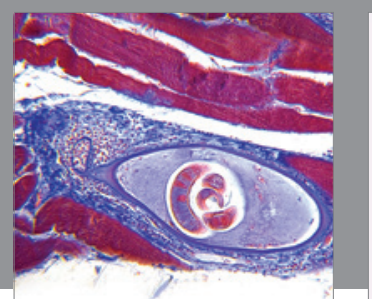

Gastroenterology Research and Practice

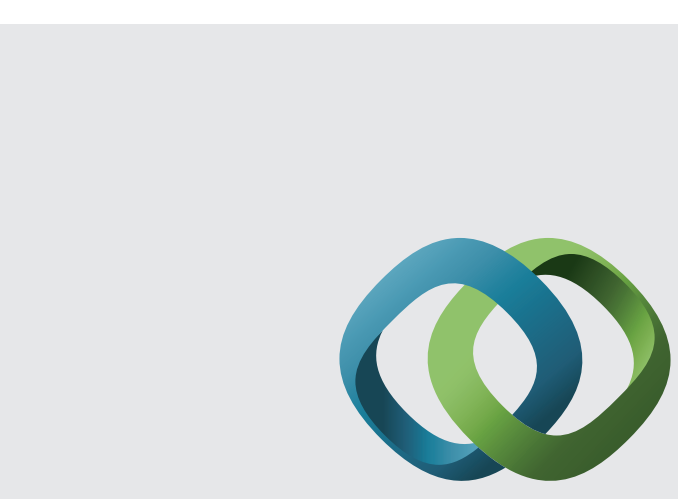

\section{Hindawi}

Submit your manuscripts at

http://www.hindawi.com
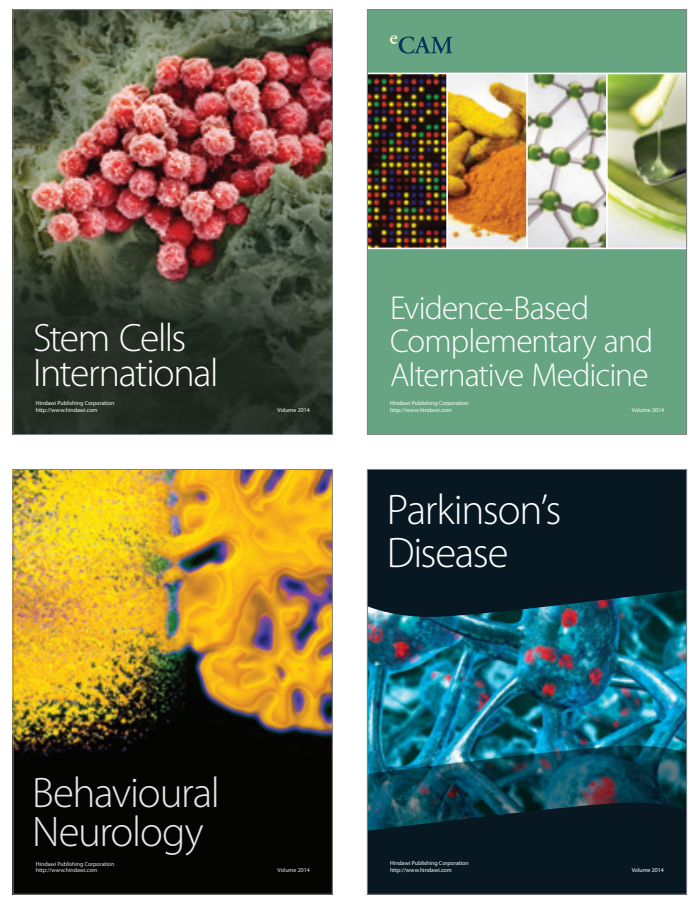
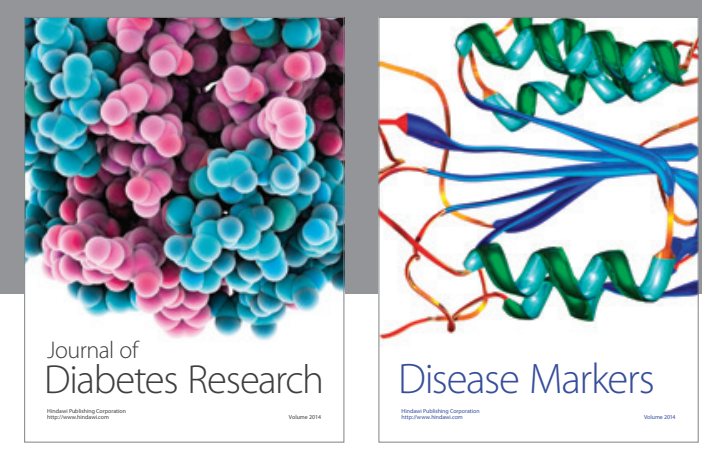

Disease Markers
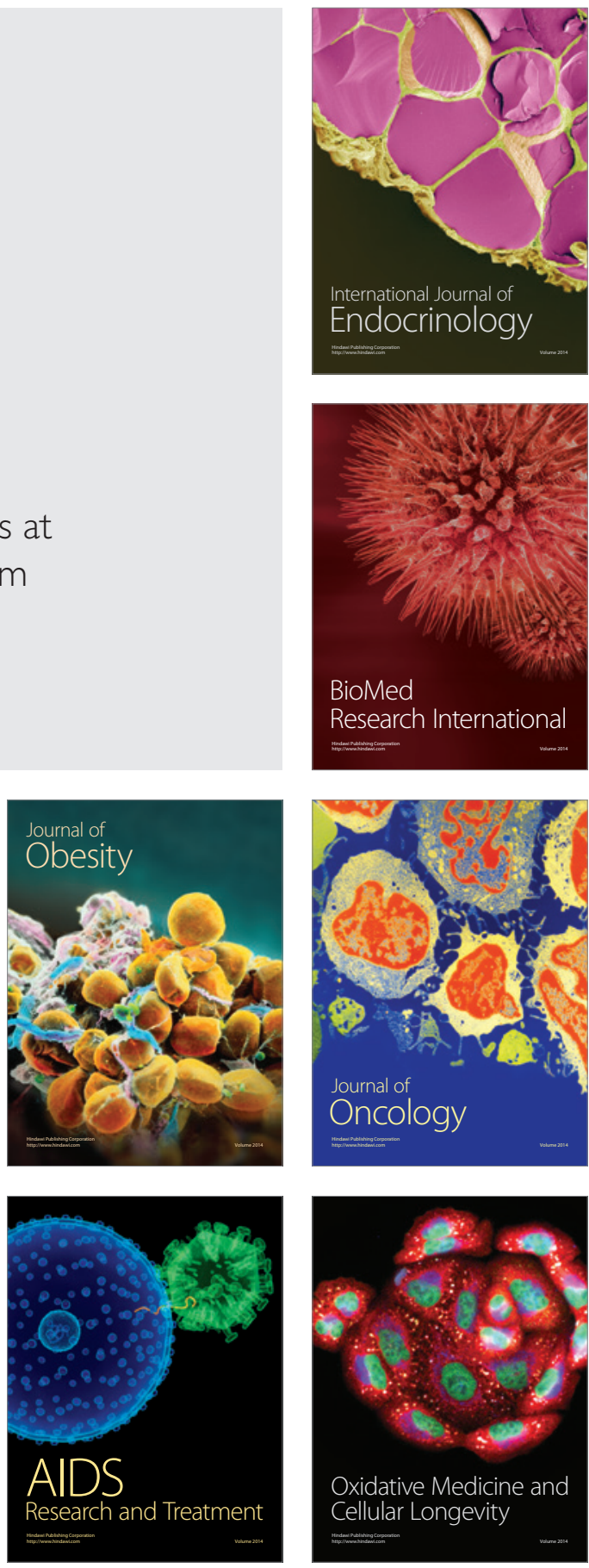